and reefs of that age is difficult. Deep-sea $\delta^{18} \mathrm{O}$ records (including some new data presented at the symposium) show isotopic depletions during MIS 11 that are consistent with a sea-level high, but in the isotope records the effects of warmer temperatures cannot be easily untangled from the effects of decreased ice volume.

To produce such a high sea level would require the collapse of at least one major ice sheet (candidates include the West Antarctic and Greenland Ice Sheets). The stability of these ice sheets in the face of high-latitude warming is one of the main questions in climate-change research.

These extremes in the ocean's thermal and geochemical state all lower its ability to hold $\mathrm{CO}_{2}$, leaving more in the atmosphere. First, $\mathrm{CO}_{2}$ is less soluble in a warmer ocean. Second, as sea level and surface temperature rise, a greater proportion of biological production is in the form of calcium carbonate. This increased production and burial of calcium carbonate lowers the ocean's alkalinity, again reducing its ability to hold on to $\mathrm{CO}_{2}$. Third, decreased biological production of soft tissue reduces the export of carbon from the surface (in contact with the atmosphere) to the deep ocean ${ }^{5}$. These changes in the ocean's carbonate-carbon cycle during MIS 11 point to what might be an important set of interactions between temperature, ecology and $\mathrm{CO}_{2}$. Model simulations of oceanic $\mathrm{CO}_{2}$ uptake have recently begun to take such feedbacks into account ${ }^{6}$.

Was the stage- 11 warming driven by increased atmospheric $\mathrm{CO}_{2}$ concentrations? The Vostok ice core now provides a palaeoclimate record extending to about 425,000 years ago $^{7}$. Preliminary measurements suggest that atmospheric $\mathrm{CO}_{2}$ levels during stage 11 are comparable to those of later interglacials, which would mean that the link between warming mechanisms and the carbon cycle may not be so simple. However, ice disturbance at the stage-11 level may have altered the $\mathrm{CO}_{2}$ record (D. Raynaud, LGGE, Grenoble).

The symposium addressed only some of the evidence from and implications of the stage-11 warm interval. Was the climate stable, or punctuated by high-frequency 'flickers'? What was the global distribution of sea-surface temperature? Stage 11 has not been studied in detail, in part because few climate records have reached it. But new cores, extracted by Ocean Drilling Program technology and long gravity-driven piston cores in high-accumulation-rate drift deposits, are beginning to provide more evidence.

Stage 11 may provide some important perspectives on future climate change. Are we adding greenhouse gases to a climate that, left to its own devices, should be on the way into another glaciation, as in the short-lived stage 5; or one that would stay warm, or get warmer, for another 40,000 years, as in stage 11? Are we setting in motion a chain of biogeochemical feedbacks that will add an oceanic contribution to the anthropogenic greenhouse-gas enrichment?

William R. Howard is at the Cooperative Research Centre for the Antarctic and Southern Ocean Environment, University of Tasmania, GPO Box 252-80, Hobart, Tasmania 7001, Australia.

1. Burckle, L. H. Quat. Sci. Rev. 12, 825-831 (1993).

2. Imbrie, J. et al. Paleoceanography 8, 699-735 (1993).

3. Farrell, J. \& Prell, W. L. Paleoceanography 4, 447-466 (1989).
4. Pirrazoli, P. A. Mar. Geol. 109, 221-236 (1993).

5. Broecker, W. S. \& Peng, T.-H. in The Global Carbon Cycle (ed. Heimann, M.) 95-115 (Springer, New York, 1993).

6. Sarmiento, J. \& Le Quéré, C. Science 274, 1346-1350 (1996).

7. Petit, J. R. et al. Nature 387, 359 (1997).

8. Howard, W. R. \& Prell, W. L. Paleoceanography 7, 79-118 (1992).

9. Ruddiman, W. F., Raymo, M. E., Martinson, D. G., Clement, B. M. \& Backman, J. Paleoceanography 4, 353-412 (1989).

10. Oppo, D. W., Fairbanks, R. G., Gordon, A. L. \& Shackleton, N. J. Paleoceanography 5, 43-54 (1990).

11. Howard, W. R. \& Prell, W. L. Paleoceanography 9, 453-482 (1994).

12. Berger, A. L. Quat. Res. 9, 139-167 (1978).

\title{
Protein engineering
}

\section{Reading, writing and redesigning}

\section{Michael Groß and Kevin W. Plaxco}

N ature doesn't have a protein-folding problem — but we do. Although we know that the line-up of the aminoacid building-blocks in a protein encodes the architecture of its correctly folded (native) form, we still cannot properly read or write this code. That is, we find it difficult to predict structures from sequences, or to design sequences that fold into a desired structure. In 1994, this dilemma prompted George Rose and Trevor Creamer ${ }^{1}$ to offer a cash prize for the solution to a specific proteindesign problem. And in this month's issue of Nature Structural Biology, Lynne Regan and co-workers report ${ }^{2}$ that they have redesigned a protein into an entirely different fold by exchanging only $50 \%$ of its amino acids. This remarkable achievement has earned them the prize, less than four years after it was announced.

Engineering prizes have, arguably, driven technological advances in the past - from the first human-powered flight across the English Channel (Kremer prize), to the first steps in nanotechnology (Feynman prize). The protein-design equivalent of the first cross-Channel flight is the 'Paracelsus chal- a

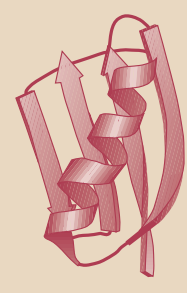

B1 domain b

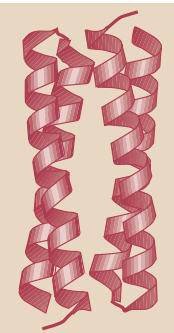

Janus lenge', named after the sixteenth-century Swiss physician, philosopher and alchemist. In an editorial in Proteins, Rose and Creamer proposed the challenge, pledging $\$ 1,000$ for the first person to show a pair of proteins which have distinctly different topologies, but which retain no less than $50 \%$ sequence identity. Such pairs are not found in nature - databases show that pairs of proteins sharing 25\% of their amino-acid residues usually have very similar structures ${ }^{3}$.

An identity score of $50 \%$ between two natural protein sequences would convince any biochemist that the proteins must be nearly identical in structure. On the other hand, because the structural identity of a protein is determined by roughly a quarter of its building blocks, the task - which is a bit like turning this article into a report about a tennis match by exchanging only half of the words - is a realistic one. In the language of proteins, most of the words seem to be space fillers that do not convey a specific meaning, so the challenge is to find the important words and rewrite them. Regan and coworkers have met the challenge with style. Rather than simply converting a given pro- c

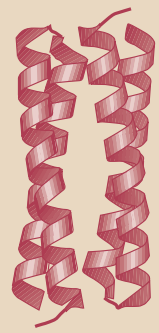

Rop
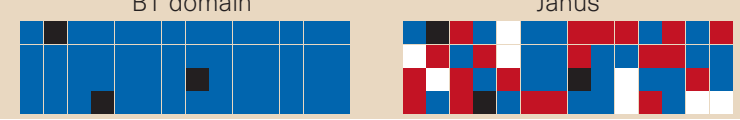

Figure 1 The two faces of protein folding. Dalal et al. ${ }^{2}$ have risen to meet the 'Paracelsus challenge', by designing a pair of proteins that have completely different folds yet have no less than $50 \%$ sequence identity. a, The starting material was the B1 domain of the streptococcal IgG-binding protein G, which is mainly $\beta$-sheet. b, By modifying just 28 of the 56 amino acids in this region, they created a new protein which they called Janus. Janus has $50 \%$ sequence identity with the B1 domain, yet its mainly helical structure resembles that of the RNA-binding protein Rop. $c$, Rop, a homodimeric fourhelix bundle protein. Blue boxes, residues from B1; red boxes, residues from Rop; black boxes, residues that are identical in $\mathrm{B} 1$ and Rop; white boxes, residues from neither $\mathrm{B} 1$ nor Rop. 
tein into whatever different structure was the most easily attainable, they specifically set out to convert the B1 domain of protein G, which consists of a four-stranded $\beta$-sheet packed against a single helix ${ }^{4}$, into a new protein with the folded structure of another protein, Rop (repressor of primer). Rop is an RNA-binding protein that folds as two helices associating to form a four-helix bundle ${ }^{5}$. Their strategy was to identify the key residues of the B1 domain that encode its mostly $\beta$-sheet structure, and to replace those residues with the corresponding, structurally critical amino acids of Rop.

What are the essential features of a protein that we have to specify to define its fold? There are four important goals, all of which aspiring protein designers must achieve ${ }^{6}$. The first is to initiate and terminate elements of secondary structure (the helices and $\beta$-sheets that are shown as ribbons in structure cartoons; Fig. 1). The second is to create a hydrophobic core - a congregation of water-avoiding amino-acid side chains whose reluctance to be exposed to the solvent will stabilize the correctly folded structure. The third goal is to supply sequences that encode loops and hairpin turns in the protein backbone, to connect sequential, secondary-structural elements. Finally, specific tertiary links need to be created; that is, energetically favourable interactions between amino acids that are distant in the sequence.

Following this logic, to swap the protein identities Regan and co-workers first had to replace residues that had an empirically observed tendency to form sheets, with other residues that prefer to be in a helix. Then they constructed the appropriate core structure based on their previous characterization of simplified core variants of Rop ${ }^{7,8}$. They also pinched from the Rop sequence a salt bridge (a pair of oppositely charged amino acids) and a single tyrosine residue as a spectroscopic probe of the folded state.

These modifications account for 28 amino acids - exactly $50 \%$ of the original B1 sequence. As well as the 56 residues that form the helices (and were the design target in this study), Rop has an unstructured 'tail' of seven residues. This was found to be essential for the good water solubility of Rop, although not for its structure, and it was also included in the design.

The new protein was fittingly called Janus (Fig. 1), as it looks like the B1 domain on the sequence level but was expected to show the face of Rop on the structural level. Regan's group cloned Janus into bacteria so they had enough material for structural investigations and could address the crucial question does Janus really look both ways? As they had predicted, Janus showed the circular dichroism and nuclear magnetic resonance signatures, isotope-exchange properties and highly cooperative unfolding that would be expected of a folded protein with the structure of Rop.
Based on these results, it was agreed that Janus had met the criteria of the challenge, and Regan was awarded the Paracelsus prize in a small ceremony last month.

Although this achievement is an impressive demonstration of just how far our knowledge of the determinants of protein structure has come, a few questions remain. For example, can the limit of sequence identity be pushed higher than $50 \%$, and can the transformation be done in the opposite direction? Regan's group is now addressing the limits of the sequence identity by reverting the changes made from B1 to Janus, one by one. But it might be more difficult to do the transformation in the opposite direction, as the formation of $\beta$-sheet structures depends on interactions between sites that may be far apart in the sequence. Still, the demonstration that protein designers now know which half of the text they have to rewrite to change a protein fold means that, one day, we will be able to read and write the code of protein folding.

Michael Groß is at the Oxford Centre for Molecular Sciences, Oxford OX1 3QT, UK. Kevin W. Plaxco is in the Department of Biochemistry, University of Washington, Seattle, Washington 98195, USA.

1. Rose, G. D. \& Creamer, T. P. Proteins Struct. Funct. Genet. 19, 1-3 (1994).

2. Dalal, S., Balasubramanian, S. \& Regan, L. Nature Struct. Biol. 4, 548-552 (1997).

3. Chothia, C. \& Lesk, A. M. EMBO J. 5, 823-826 (1986).

4. Gronenborn, A. M. et al. Science 253, 657-661 (1991).

5. Banner, D. W., Kokkinidis, M. \& Tsernoglou, D. J. Mol. Biol. 196, 657-675 (1987).

6. Cordes, M. H. J., Davidson, A. R. \& Sauer, R. T. Curr. Opin. Struct. Biol. 6, 3-10 (1996).

7. Munson, M., O'Brien, R., Sturtevant, J. M. \& Regan, L. Prot. Sci. 3, 2015-2022 (1994).

8. Munson, M. et al. Prot. Sci. 5, 1584-1593 (1996).

\section{Sociology of science}

\section{Irregular scientific conjugations}

The perception of behaviour varies with the distance of the observer from the subject. This variation generally extends along a continuum but, in the special case of the behaviour of scientists, three primary clusters of distance seem particularly important. These can be defined as identity (I), unrelatedness $(U)$ and separated/heterologous (S/he). Results in ten areas of behavioural perception within science can thus be summarized as irregularly conjugating verbs.

I construct precise and logical sentences You write in a standard scientific style She produces incomprehensible papers riddled with jargon

I am frequently asked to appear in TV science documentaries

You are a typical eccentric media-friendly boffin

He is a self-promoting pseudoscientific media whore

\section{I am a polymath}

You are a jack of all trades

She has views on subjects she knows

nothing about

I publish every finding for the wider scientific community

You have a refined strategy for

building an impressive publications list

They are salami slicing

I am a confident speaker in panel discussions You are charmed by the sound of your own voice

He shouts down the views of other participants

I have a reputation that enables me to attract bright young scientific talent You have a reputation maintained by a highly able team of collaborators He has a reputation for exploiting poorly paid postdocs
I ensure that a company's scientific approach is up to date

You reassure investors by your presence on the Scientific Advisory

Board

He receives a fat retainer simply because he has a Nobel prize

I undertake peer-review carefully and thoroughly

You delay returning your comments on the paper

She conducts additional experiments for her own paper while the manuscript languishes in her pending tray

I do not publish preliminary data You conduct follow-up experiments in order to maintain a scientific lead over competitors

He hoards data until his industrial collaborators have filed patents

I actively solicit and review high-quality papers

You provide useful comments on the occasional manuscript

They are only on the editorial board to preserve the façade of geographical balance

\section{John Hodgson}

John Hodgson is a senior editor of Nature Biotechnology. 